\title{
MENGEMBANGKAN DAN MENGOPTIMALKAN MEDIA PEMBELAJARAN PENDIDIKAN DALAM ASPEK TEKNOLOGI DI DESA REJOTANGAN
}

\author{
Rohmatus Syafi'ah ${ }^{1}{ }^{*}$, Nourma Oktaviarini ${ }^{2}$, Nurna Listya P. ${ }^{3}$ \\ 1,2Universitas Binneka PGRI, Tulungagung, Indonesia \\ ${ }^{3}$ Universitas Binneka PGRI, Tulungagung, Indonesia \\ *Penulis Koresponsensi, email: syafiahzainul@gmail.com
}

Received:06/10/2021

Revised:11/10/2021

Accepted:11/10/2021

\begin{abstract}
The results of observations in the village of Rejotangan Tulungagung show that the obstacles experienced by students who are in elementary school in online learning are the limited use of learning technology, which is caused by the absence of guidance from both teachers and parents in the use of learning technology in the digital era. Learning is carried out only through WhatsApp (WA) group media for sharing materials and giving assignments without using other digital learning media. The condition of the lack of knowledge on the use of learning technology in the digital era will certainly be a long-term obstacle if it is not overcome, therefore this program of community service activities in the village of Rejotangan Tulungagung is held to optimize and develop educational learning media, especially for elementary school teachers or equivalent. Results of the interview with Wakakur MIN 5 Tulungagung, Rejotangan village, it is known that the media used in online learning is WA group and google classroom which causes students to be less enthusiastic. This community service activity aims to introduce and assist MIN 5 Tulungagung teachers in making effective learning media using Kinemaster which is later expected to increase student enthusiasm in online learning. The method of implementing the activities is in the form of a problem solving framework and the realization of problem solving. The targets in this activity are 15 teachers from low and high grades. The result of this activity is the achievement of the target of $80 \%$ which means the activity is successful and the participants are enthusiastically followed from beginning to end. The obstacle in this activity is that there are 2-3 teachers whose cellphone memory is not sufficient to download the kinemaster application. The follow-up to this activity is that similar activities are carried out with a longer time.
\end{abstract}

Keywords: kinemaster, learning media, online learning.

Abstrak. Hasil observasi di desa Rejotangan Tulungagung menunjukkan bahwa kendala yang dialami siswa yang duduk di bangku sekolah dasar (SD) dalam pembelajaran daring adalah keterbatasan pemanfaatan teknologi pembelajaran, yang diakibatkan tidak adanya bimbingan baik dari guru ataupun orang tua dalam pemanfaatan teknologi pembelajaran di era digital. Pembelajaran yang dilakukan hanya melalui media WhatsApp (WA) group saja untuk sharing materi dan pemberian tugas tanpa memanfaatkan media pembelajaran digital yang lain. Kondisi minimnya pengetahuan terhadap pemanfaatan teknologi pembelajaran di era digital ini tentu akan menjadi kendala dalam jangka panjang bila tidak diatasi, oleh karena itu program kegiatan dari pengabdian masyarakat di desa Rejotangan Tulungagung ini diadakan untuk mengoptimalkan dan mengembangkan media pembelajaran pendidikan khususnya untuk guru SD atau sederajat. Hasil wawancara dengan Wakakur MIN 5 Tulungagung desa Rejotangan diketahui bahwa media yang digunakan dalam pembelajaran daring adalah WA group dan google classroom yang menyebabkan siswa kurang antusias. Kegiatan pengabdian masyarakat ini bertujuan untuk mengenalkan dan mendampingi guru MIN 5 Tulungagung dalam pembuatan media pembelajaran yang efektif dengan menggunakan Kinemaster yang nantinya diharapkan dapat meningkatkan antusias siswa dalam pembelajaran daring. Metode pelaksanaan kegiatan berupa kerangka pemecahan masalah dan realisasi pemecahan masalah. Target sasaran dalam kegiatan ini adalah 15 guru dari kelas rendah dan kelas tinggi. Hasil kegiatan ini adalah ketercapaian target sasaran sebesar $80 \%$ yang artinya kegiatan berhasil dan diikuti peserta dengan penuh antusias dari awal sampai akhir. Kendala dalam kegiatan ini adalah adanya 2-3 orang guru yang memory HP tidak mencukupi untuk download aplikasi kinemaster. Tindak lanjut kegiatan ini adalah kegiatan serupa dilakukan dengan waktu yang lebih panjang.

Kata Kunci: kinemaster, pembelajaran daring, media pembelajaran

How to Cite: Syafi'ah, R., Oktaviarini, N., \& Listya P., N. (2021). Mengembangkan dan Mengoptimalkan Media Pembelajaran Pendidikan dalam Aspek Teknologi di Desa Rejotangan. Mitra Mahajana: Jurnal Pengabdian Masyarakat, 2(3), 250-257. doi: https://doi.org/10.37478/mahajana.v2i3.1272

\section{PENDAHULUAN}

Perkembangan zaman yang semakin pesat seiring berkembanganya IPTEK menjadikan manusia harus mampu beradaptasi jika ingin terus bertahan. Hal yang terjadi di Indonesia dan 
negeri lain di dunia saat ini adalah penyesuaian dengan kehidupan baru akibat pandemi covid 19. Salah satu penyesuaian dalam bidang adalah diterapkannya pembelajaran daring. Pandemi covid 19 disebabkan oleh Coronavirus Diseases 2019 (COVID19) suatu penyakit baru yang belum pernah teridentifikasi pada manusia. Tanggal 30 Januari 2020 ditetapkan oleh WHO sebagai kedaruratan kesehatan masyarakat. Covid 19 sangat berdampak pada seluruh aspek kehidupan seperti ekonomi, pariwisata, sosial, dan pendidikan.

Aspek pendidikan, tepatnya tanggal 18 Mei 2020 Menteri Pendidikan dan Kebudayaan Republik Indonesia mengeluarkan Surat Edaran Nomor 15 Tahun 2020 yang berisi tentang proses belajar yang dilaksanakan dengan pembelajaran jarak jauh dari rumah atau pembelajaran dalam jaringan (daring) yang difokuskan pada pendidikan kecakapan hidup antara lain mengenai pandemi Covid-19. Kondisi ini memaksa semua dilaksanakan secara mendadak sehingga sebagian besar tidak sesuai dengan apa yang telah direncanakan. Faktor yang menjadi penyebab ketidaksesuaian tersebut diantaranya adalah kesiapan sekolah, guru, peserta didik, orang tua, serta akses internet. Hal ini senada dengan yang disampaikan oleh (Tian, Desi, Hardini, \& Indriani, 2021) bahwa tidak semua peserta didik akan sukses dalam pembelajaran online dikarenakan faktor lingkungan belajar dan karakteristik peserta didik.

Observasi awal yang dilakukan di Desa Rejotangan Tulungagung pada sektor pendidikan ditemukan beberapa kendala yaitu khususnya pada problematika pembelajaran daring. Berdasarkan saran dan arahan dari Bapak Kepala Desa untuk mengetahui permasalahanpermasalah pembelajaran daring langsung ke sektor lembaga MI/SD di sekitar Desa Rejotangan. MIN 5 Tulunguang merupakan Madrasah Ibtidaiyah Negeri yang selama ini memiliki beberapa macam kendala dan faktor-faktor kesulitan dalam pembelajaran daring. Melalui hasil wawancara dengan Wakil Kurikulum Bapak Choirul Anam menyatakan bahwa kesulitan ditingkat guru adalah pemanfaatan media digital yang memungkinkan memotivasi proses pembelajaran menjadi kegiatan yang menyenangkan dan inovatif, pembelajaran yang dilakukan hanya melalui Watshap Grup (WA) group dan Google Clasroom saja untuk sharing materi dan pemberian tugas tanpa memanfaatkan media pembelajaran digital yang lain. Hal ini menyebakan kejenuhan bagi siswa sehingga siswa cenderung menggunakan handpone untuk bermain saja.

Dari semua permasalah tersebut, guru sebagai tenaga pendidik harus mampu merencanakan dan membuat kajian materi atau bahan ajar sesuai tuntutan kurikulum 2013. Faktor penunjnag lainnya adalah penggunaan dan pengembangan media pembelajaran yang inovatif dan menyenangkan. Salah satu cara yang dapat digunakan untuk menarik minat dan motivasi siswa dalam pembelajaran daring adalah penggunaan media pembelajaran berupa video pembelajaran dan video animasi yang dibuat oleh guru sendiri. Media video pada masa pandemic Covid seperti sekarang ini juga bisa digunakan sebagai alternative kehadiran guru yang tidak bisa menjelaskan secara bertatap muka. Media pembelajaran digunakan sebagai sarana penyampaian informasi dari sumber ke penerimanya dalam hal ini adalah siswa agar pembelajaran berlangsung efektif (Asyar, 2012).

Pada saat ini media pembelajaran daring belum sepenuhnya berkembang dan diimplementasikan oleh guru pada proses pembelajaran. Salah satu yang menjadi masalah atau problem yaitu para guru yang kurang ahli dalam menggunakan berbagai media berbasis ICT, sehingga pengembangan materi pembelajaran dengan sistem android atau komputer kurang optimal. Pendidikan berbasis ICT menekankan keaktifan siswa dan pembelajaran berpusat pada siswa (Arifin \& Adhi, 2012). Sebagaian besar siswa kurang memahami materi pembelajaran daring yang hanya berupa foto yang dikirim di grup WA saja tanpa adanya penjelasan dari guru. Hal ini juga menjadikan orang tua siswa terutama orang tua siswa sekolah dasar yang harus mendampingi dan membibing putra putrinya belajar di rumah mengalami kebingungan. Oleh karena itu sebagai seorang pendidik dalam hal ini guru dituntut untuk lebih kreatif dan inovatif dalam pembelajaran daring dengan memanfaatkan teknologi seperti pembuatan video pembelajaran menggunakan aplikasi kinemaster atau aplikasi lain. Penggunaan variasi dalam 
pembelajaran seperti pembuatan video pembelajaran mampu menjadikan suasana pmebelajran yang hidup dan tidak membuat bosan kegiatan yang membosankan (Hamimah, 2012).

KineMaster merupakan aplikasi yang dapat di download di playsotore pada HP android yang menyediakan fitur lengkap pengeditan video yang dapat digunakan oleh guru untuk membuat video pembelajaran sederhana berkulaitas tinggi karena aplikasi ini didukung bannyak lapisan video, audio, gambar, teks, dan efek (Fajariyah, 2018). Agar siswa fokus pada video pembelajaran yang dibuat materi pembelajaran dapat didesain semenarik mungkin dengan dilengkapi animasi dan efek lain yang kira-kira disukai oleh anak usia SD. Video pembelajaran yang telah dibuat dengan kinemaster dapat langsung dibagikan ke media sosial antara lain WhatsApp, YouTube, WhatsApp, Google+, facebook dan lain lain yang akan memudahkan guru dalam mempublikasikan video yang telah dibuat dan memudahkan siswa dalam mengakses materi pembelajaran, sehingga diharapkan dapat meningkatkan antusias siswa dalam mengikuti pembelajaran daring (Khaira, 2020).

Kondisi minimnya pengetahuan terhadap pemanfaatan teknologi pembelajaran di era digital akan menjadi hambatan dalam jangka panjang jika tidak diatasi, oleh karena itu program kegiatan dari pengabdian masyarakat di desa Rejotangan Tulungagung ini diadakan untuk mengoptimalkan dan mengembangkan media pembelajaran pendidikan khususnya guru MI atau sederajat dalam aspek teknologi dengan cara melakukan pendampingan guru MIN 5 Tulungagung di desa Rejotangan dalam memanfaatkan media pembelajaran berbasis teknologi berupa pembuatan video pembelajaran dengan aplikasi KINEMASTER.

Kegiatan pengabdian ini memiliki tujuan tentunya adalah setelah dilakukan pendampingan dalam mengoptimalkan media pembelajaran pendidikan berbasis teknologi Kinemaster guru menjadi lebih terampil dan kreatif dalam mengembangkan media pembelajaran yang menarik melalui aplikasi kinemaster, sehingga menjadikan siswa semangat dalam mengikuti pembelajaran daring. Tujuan akhirnya adalah anak sekolah dasar dapat mengikuti pembelajaran daring dengan penuh semangat dan antusias.

\section{METODE PELAKSANAAN}

\section{Kerangka Pemecahan Masalah}

Memberikan Sosialisasi terkait pemanfaatan media pembelajaran Kinemaster pada Pembelajaran Daring di MIN 5 Tulungagung yang diselenggarakan pada tanggal 23 September 2021. Kegiatan ini dilaksanakan di Lembaga Pendidikan MIN 5 Tulungagung, dengan jumlah sasaran sosialisasi sebanyak 15 guru MIN Tulungagung. Kegiatan Pengabdian Masyarakat ini dibantu oelah tim Mahasiswa KKN Universitas Bhinneka PGRI di desa.

\section{Realisasi Pemecahan Masalah}

Langkah-langkah persiapan dalam pengabdian masyarakat di desa Rejotangan sebagai berikut:

a. Setelah mendapatkan rekomendasi dari Kepala Desa Rejotangan tim dosen dan mahasiswa melakukan perijinan dan observasi awal serta wawancara kepada Kepala Sekolah MIN 5 Tulungagung terkait kendala pembelajaran dari dan media pembelajaran daring yang digunakan pada masa pandemi.

b. Menyiapkan tim dosen dan mahasiswa untuk transfer pengetahuan. Persiapan tim yang matang sangat diperlukan sebelum kegiatan sosialisasi dan pendampingan dilaksankan pada guru MIN 5 Tulungagung di desa Rejotangan. Dari Tim dosen dan mahasiswa menyiapkan flayer kegiatan, materi, dan banner sesuai tema kegiatan pengabdian masyarakat.

c. Selain mempersiapkan flayer untuk kegiatan, tim dosen dan mahasiswa pada pengabdian masyarakat juga menyiapkan materi. Ada 2 materi yang nantikan akan dipresentasikan oleh perwakilan dosen dan perwakilan mahasiswa. Materi yang disampaikan oleh dosen berisi materi terkait kajian umum pembelajaran dengan menggunakan media KInemaster. 
Sedangkan materi yang kedua berisikan materi terkait teknik dalam mengaplikasikan Kinemaster dalam penyampaian materi di kelas 1 sampai 3 SD.

d. Selanjutnya setelah kedua materi sudah dipersiapkan selanjutnya dari tim mahasiswa mempersiapkan contoh materi pembelajaran Simbiosis Mutualisme yang sudah menggunakan Aplikasi Kinemaster.

e. Tim mahasiswa dan tim dosen diberikan kesempatan untuk sharing pengetahuan tentang media pembelajaran dengan Kinemaster pada guru MIN 5 Tulungagung di desa Rejotangan dengan menerapkan protokol kesehatan.

f. Membuat forum tanya jawab seputar optimalisasi media pembelajaran pendidikan aspek teknologi untuk anak usia SD/MI. Langkah-langkah tersebut diharapkan dapat menajdikan siswa SD/MI menjadi lebih semangat dalam mengikuti pembelajaran daring dan mampu memanfaatkan beragam media pembelajaran dalam aspek teknologi.

Metode kegiatan pada pengabdian masyarakat ini Praktek langsung di MIN 5 Tulungagung dengan tahapan sebagai berikut:

a. Pemaparan materi pertama oleh tim dosen kepada guru MIN 5 Tulungagung tentang media pembelajaran Kinemaster. Pemaparan ini membahas tentang berbagai macam media pembelajaran yang dapat dimanfaatkan oleh anak SD/MI berikut cara mengakses dan mempergunakannya. Dilajutkan dengan sesi tanya jawab untuk memastikan materi yang disampaikan dapat diterima oleh guru MIN 5 Tulungagung dengan baik. Pada hari pertama ini pemateri mengenalkan salah satu aplikasi pembelajaran yaitu Kinemaster. Keunggulan dan kelemahan kinesmater dan mengarahkan peserta kegiatan menganalisa Kinemaster secara umun serta mengarahkan Guru MIN 5 Tulungagung untuk mendowload Kinemaster pada Handphone masing- asing melalui Playstore.

b. Materi kedua dipresentasikan oleh tim mahasiswa memaparkan tutorial pembuatan video pembelajaran dengan menggunakan Kinemaster dan penjelasakn tentang fitu-fitur pembelajaran yang dapt digunakan oleh Guru untuk melakukam atifitas pembelajaran. Selain itu tim juga menunjukkan video pembelajaran materi SD/MI yang telah dibuat dengan menggunakan KINEMASTER kepada peserta (Guru MIN 5 Tulungagung). Selanjutnya baik pemateri 1 maupun 2 melakukan pendampingan praktik pembuatan video pembelajaran dengan kinemaster.

c. Kegiatan selanjutnya, pemateri melakukan refleksi dari hasil materi dan pendampingan praktik yang sudah dilaksanakan dengan cara berkeliling kelas pendampinggan dengan wawancara tidak tidak struktur kepada Bapak Ibu Guru di MIN 5 Tulungagung.

\section{HASIL DAN PEMBAHASAN}

Perizinan dan koordinasi pelaksanaan kegiatan oleh dosen dan mahasiswa pada awal program kegiatan pengabdian pada masyarakat. Kegiatan koordinasi ini sebelumnya dilaksanakan bersama dengan Kepala Desa Rejotangan yang memberikan informasi bahwasanya ada beberapa lembaga pendidikan di Desa Rejotangan yang mengalami kendalam dalam pembelajaran daring. Hingga pada akhirnya didampingi Surat Ijin dari Kepala Desa Rejotangan Tim Dosen dan Tim Mahasiswa langsung melakukan koordinasi selanjutnya ke MIN 5 Tulungagung. Hasil Koordinasi dengan Lembaga Pendidikan MIN 5 Tulungagung yaitu dengan Bapak Zainal Panani, S.Pd selaku Kepala Sekolah menyatakan bahwa memperkenankan dan mengijinkan untuk melakukan kegiatan sosialisasi Media Pembelajaran Kinemaster. Setelah perijinan selesai selanjutnya koordinasi terkait waktu, tanggal dan ruangan kegiatan. Dari hasil kesepakatan akhirnya kegiatan dilaksanakan di tanggal 23 September 2021 di Ruang Aula MIN Tulungagung dengan waktu jam 11.00-13.00.

Koordinasi selanjutnya diarahkan langsung dengan Bapak Choirul Huda selaku Waka Kurikulum. Dari hasil wawancara dengan bapak Waka Kurikulum yaitu praktek penyampaian materi masih sebatas share video dari youtube melalui google classroom, kemudian untuk 
penugasan sudah menggunakan google form. Untuk kegiatan pembelajaran dengan sistem video dan editing dengan menggunakan Kinemaster hanya beberapa guru saja yang menggunakan. Untuk guru kelas bawah cenderung masih sebatas share video dari youtube. Maka kegiatan pengabdian masyarakat ini dengan tujuan membantu guru MIN 5 Tulungagung dalam meningkatkan keterampilan editing video dalam penyampaian materi ajar agar menghasilkan kegiatan pembelajaran yang menarik, sehingga kebingungan siswa terkait pembahasan materi bisa terselesaikan dengan bantuan penjelasan video editing dari guru melalui Kinemaster. Hal ini sejalan dengan hasil penelitian yang dilakukan oleh (Widiono, 2021) yang menyatakan bahwa penerapan aplikasi Kinemaster dapat dijadian salah satu alternatif dalam mengembangkan media pembelajaran yang inovatif.

Kegiatan penyusunan materi oleh tim dosen dan tim mahasiswa mengkaji pustaka dari berbagai sumber referensi yang sesuai dengan pengetahuan dasar videografi dengan Kinemaster. Kegiatan tersebut dilakukan pada tahap awal pelaksanaan dan digunakan pada kegiatan sosialisasi media pembelajaran Kinemaster di MIN 5 Tulungagung.

Pada kegiatan sosialisasi tim dosen menyampaikan materi mengenai fitur kinemaster yang bukan hanya menggabungkan gambar, suara, dan video, namun aplikasi ini tanpa harus pindah ke aplikasi lain dapat digunakan untuk mengedit video. Aplikasi kinemaster ini cukup mudah bisa didownload pada android maupun ios. Tim dosen bersama dengan peserta kegiatan guru MIN 5 Tulungagung juga melakukan Tanya jawab dengan guru bahwasanya bagaimana kegiatan pembelajaran selama masa pandemi dan sudah menggunakan aplikasi media pembelajaran IT apa saja dalam menerapkan materi pembelajaran. Pada penyampaian materi ini tim dosen memberikan penjelasan terkait persiapan yang matang agar pengeditan video kinemaster bisa efisien dan efektif serta inovatif untuk materi yang akan disampaikan. Persiapan-persiapan itu diantaranya adalah a) menyiapkan materi, b) memastikan tujuan tema pembelajaranya sesuai dengan kurikulum 2013, c) menulis scrip terlebih dahulu hal ini memudahkan dalam pengambilan video, d) buat video originalnya terlebih dahulu, e) buat judul yang menarik, f) barulah bisa membuka aplikasi Kinemaster dan siap melakukan editing video (Patimah, 2020).

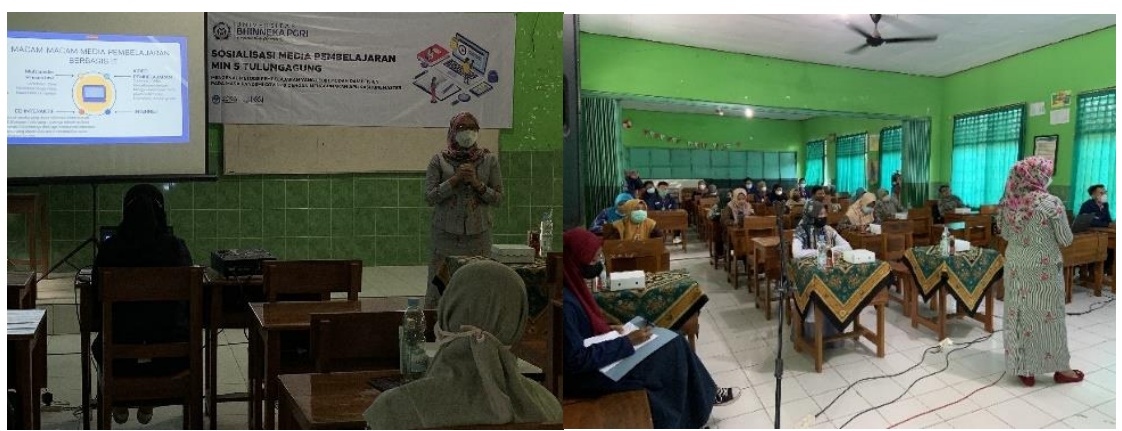

Gambar 1. Penyampaian materi oleh tim dosen

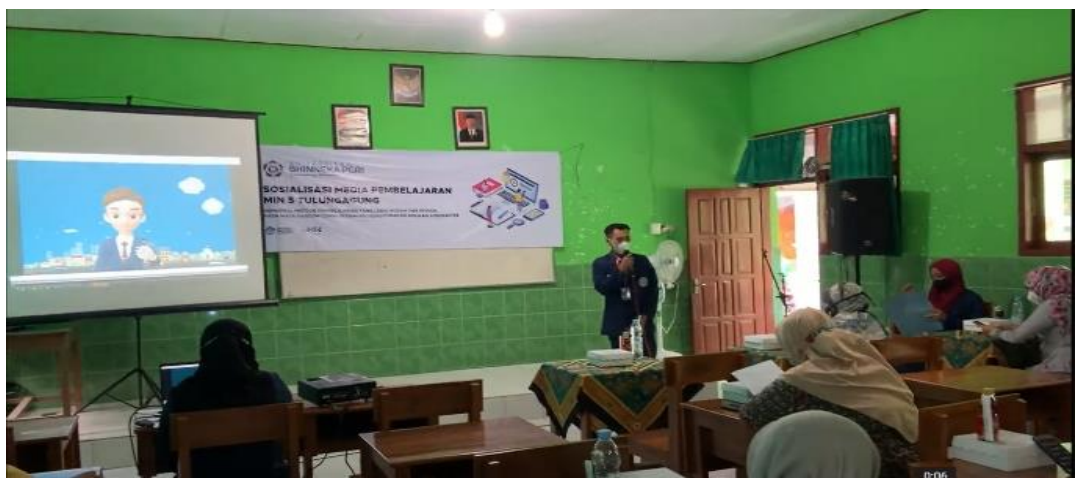

Gambar 2. Penyampaian materi oleh tim mahasiswa KKN desa Rejotangan 


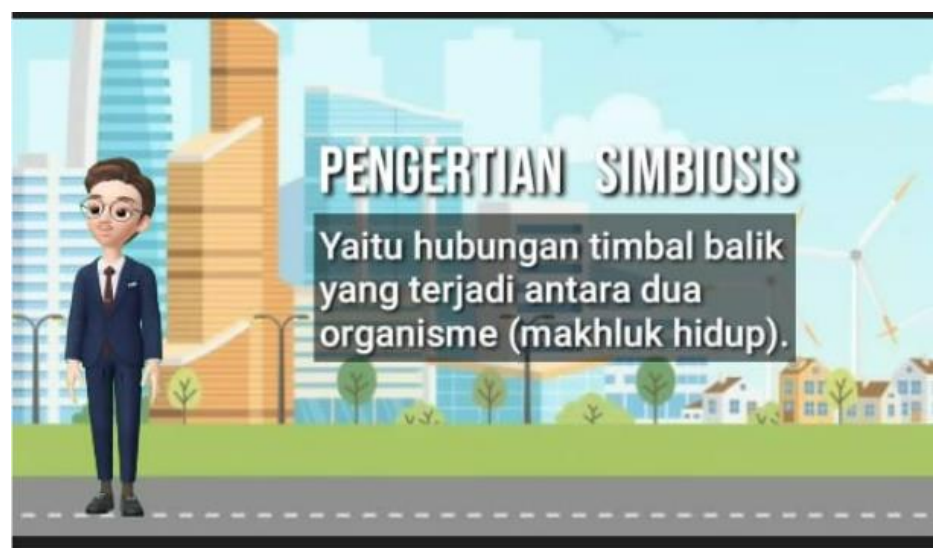

Gambar 3. Contoh video pembelajaran materi SD yang dibuat oleh tim

Pada penyampaian materi ini peserta cukup antusias diantaranya yaitu dengan memberikan pertanyaan kepada tim dosen untuk langsung saja mempraktekan di HP dan Laptop masing-masing guru. Untuk kegiatan ini akhirnya dikaitkan dengan pemateri kedua yaitu perwakilan dari mahasiwa tim KKN dengan nama Muhammad Zendi untuk menjelaskan langkah-langkahnya pembuatan video dengan kinemater. Selain itu juga ditunjukkan video pembelajaran yang telah dibuat oleh tim yaitu video pembelajaran terkait materi simbiosis untuk siswa SD/MI yang sudah melalui proses telaah dari dosen ahli, dengan tujuan menumbuhkan semangat dan minat peserta sosialisasi untuk membuat video pembelajaran serupa pada materi yang lain. Hal ini sejalan dengan penelitian yang dilakukan oleh (Amelia \& Arwin, 2020) yang menyatakan bahwa media pembelajaran berbasis aplikasi Kinemaster pada pembelajaran tematik terpadu di kelas III SD Negeri 36 Koto Panjang dinyatakan sangat layak dan sangat praktis. Selanjutnya, guru MIN Tulungagung diarahkan langsung untuk mempraktekkan. Guru MIN 5 Tulungagung merasa sangat tertantang dengan adanya sosialisasi ini dikarenakan yang tadinya lupa dengan teknik aplikasi Kinemaster sedikit banyaknya terbantu untuk kembali menggunakan aplikasi ini. Bagi guru-guru yang belum bisa menggunakan sangat terbantu karena diberikan pendampingan satu guru didampingi dengan satu mahasiswa bersama tim dosen.

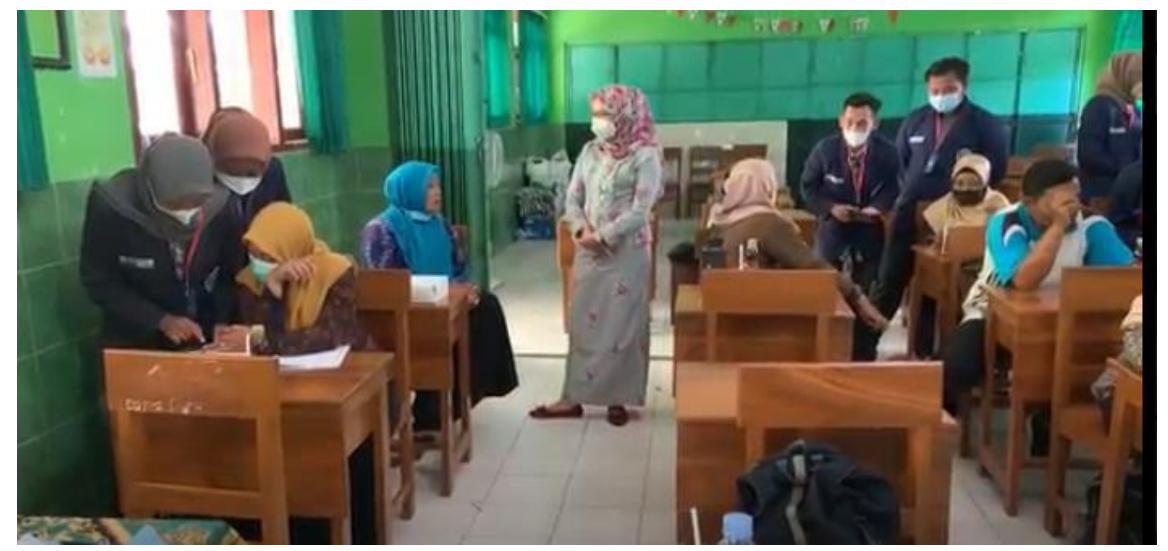

Gambar 4 Pendampingan parktik penggunaan kinemaster oleh dosen dan mahasiswa

Kegiatan diskusi dan Tanya jawab dengan peserta sosialisasi yang dikemas melalui Focus Group Discusion (FGD) merupakan kegiatan akhir. Hasil dari pengabdian masyarakat pada kegiatan sosialisasi media pembelajaran Kinemaster yaitu para peserta guru MIN 5 Tulungagung masih mengalami kebingungan dalam fungsi-fungsi icon/tombol dalam aplikasi kinemaster. Serta adanya keterbatasan karena guru belum mempersiapkan materi yang akan dijadikan dasar video editing. Sehingga waktu 3 jam memang sangat dirasakan masih kurang ketika kegiatan pendampingan dalam membuat video kinemaster. Sehingga MIN 5 Tulungagung mengarahkan untuk membuat jadwal kembali untuk pendampingan implementasi media kinemaster pada hari dan waktu lain bersama dengan tim mahasiswa. Walupun demikian, 
peserta pendampingan mengungkapkan bahwa kegiatan pendampingan yang telah dilakukan ini sangat membantu dan memacu semangat mereka dalam mengembangkan media pembelajaran menggunakan kinemaster. Hal ini sejalan dengan hasil pengabdian masyarakat oleh (Darmawiguna, 2019) dimana hasil pengebdian masyarakat yang dilakukan memperoleh respon peserta yang sangat baik dan peserta menyatakan bahwa kegiatan yang dilakukan sangat memberikan manfaat bagi peserta pelatihan dan pendampingan.

Perencanaan dalam kegiatan sosialisasi dan pendampingan di MIN 5 Tulungagung diikuti peserta sebanyak 15 guru (perwakilan guru kelas 1-6). Faktanya dalam pelaksanaannya, kegiatan hanya diikuti oleh 12 peserta dimana 11 guru berasal dari guru kelas rendah (kelas 13) dan 1 guru berasal dari kelas tinggi (kelas 4). Ketidakhadiran guru kelas tinggi terutama (kelas 5-6) dikarenakan pada hari dilaksanakan sosialisasi dan pendampingan ternyata yang masuk tatap muka hanya siswa kelas rendah yaitu kelas 1-3, sementara siswa kelas tinggi (kelas 4-6) adalah jadwal pembelajaran daring. Walaupun demikian, ketercapaian terget peserta dilihat dari peserta yang hadir sebesar $80 \%$. Hal ini menunjukkan bahwa ketercapaian target sasaran berhasil. Keberhasilan target sasaran ini diharapkan mampu memberikan keterampilan guru dalam mengembangkan media pembelajaran inovatif melalui aplikasi kinemaster yang disesuaikan dengan lingkungan dan kondisi peserta didik sesuai dengan hasil penelitian yang dilakukan oleh (Indriani \& Pangaribuan, 2020) yang menyatakan bahwa media kinemater efektif digunakan dalam pembelajaran.

Target materi sosialisasi dan pendampingan di MIN 5 Tulungagung ketercapaian mencapai $100 \%$. Seluruh materi tersampaikan dengan baik yaitu materi pengantar terkait mediam pembelajaran berbasis teknologi, dan pengembangan media pembelajaran berupa video menggunakan aplikasi kinemaster yang disampaian oleh tim dosen dan tim KKN 16 Universitas Bhinneka PGRI di desa Rejotangan. Sementara target ketercapaian tujuan sosialisasi dan pendampingan dalam mengoptimalkan media pembelajaran berbasis teknologi dengan aplikasi kinemaster cukup baik, namun masih perlu perpanjangan waktu agar semua peserta dapat mempersiapkan bahan-bahan yang lebih sesuai untuk dimasukkan dalam video pembelajaran yang dibuat dengan menggunakan aplikasi kinemaster.

\section{SIMPULAN DAN TINDAK LANJUT}

Kegiatan sosialisasi dan pendampingan berjalan dengan lancar sesuai dengan perencanaan. Kegiatan diikuti dengan penuh antusias oleh peserta, berjalan lancar dan baik. Hal ini terlihat dari antusias peserta dalam bertanya dan keikutsertaan peserta dalam kegiatan dari awal sampai akhir, meskipun tidak $100 \%$ peserta dapat mempraktikkan pembuatan media pembelajaran dengan aplikasi kinemaster dikarenakan memori HP yang tidak mencukupi utuk menginstal aplikasi tersebut. Tindak lanjut yang disarankan dari kegiatan ini adalah waktu pelaksanaan pengabdian dapat lebih dieprpanjang lagi sampai pada tahap target sasaran mampu menerapkan media yang telah dikembangkan pada peserta didik sehingga dapat diketahui pengaruh penggunaan media tersebut pada peserta didik.

\section{DAFTAR PUSTAKA}

Amelia, V., \& Arwin. (2020). Pengembangan Media Pembelajaran Berbasis Aplikasi KinemasterPada Pembelajaran Tematik Terpadu di Kelas III Sekolah Dasar. Jurnal Inovasi Pendidikan dan Pembelajaran Sekolah Dasar, 4, 88-97. Retrieved from http://ejournal.unp.ac.id/index.php/jippsd/article/view/112274/pdf

Arifin, Z., \& Adhi, S. (2012). Pengembangan Pembelajaran Aktif dengan ICT. Yogyakarta: Skripta Media Creative.

Asyar, R. (2012). Kreatif Mengembangkan Media Pembelajran. Jakarta: Gaung Persada Press,.

Darmawiguna. (2019). PELATIHAN DAN PENDAMPINGAN PEMBUATAN MEDIA PEMBELAJARAN INTERAKTIF MENGGUNAKAN PREZI DAN VIDEOSCRIBE BAGI GURU- 
GURU DI SMK NEGERI 1 NUSA PENIDA. Jurnal Pengabdian Kepada Masyarakat Widya Laksana, 8, 43-50. doi:http://dx.doi.org/10.23887/jwl.v8i1.15584

Fajariyah, L. A. (2018). Pembelajaran Teks Report dengan Proyek 'Cerdiq' Berbasis Kinemaster. Jurnal Didaktika Pendidikan Dasar, 2, 207-220. Retrieved from https://ojsdikdas.kemdikbud.go.id/index.php/didaktika/article/view/69/78

Hamimah. (2012). Pemberian Penguatan dalam Pembelajaran IPS untuk Meningkatkan Motivasi Belajar Siswa di Sekolah Dasar. Padang: Universitas Negeri Padang Repository. Retrieved from https://123dok.com/document/z1ekmrpy-pemberian-penguatan-pembelajaranmeningkatkan-motivasi-belajar-universitas-repository.html

Indriani, E., \& Pangaribuan, T. R. (2020). EFEKTIVITAS PENGGUNAAN MEDIA KINEMASTER TERHADAP. Kode Jurnal Bahasa, 154-163. Retrieved from https://jurnal.unimed.ac.id/2012/index.php/basastra/article/

Khaira, H. (2020). PEMANFAATAN APLIKASI KINEMASTER SEBAGAI. (pp. 39-44). Medan: Universitas Negeri Medan. $\quad$ Retrieved from http://digilib.unimed.ac.id/41218/1/Fulltext.pdf

Muhamad Tian, C. D. (2021). Ruang Belajar Online Sebagai Implementasi Pembelajaran Daring Pada Murid SekolahDasar Muhammadiyah 22 Meranjat. JPKMBD(Jurnal Pengabdian Kepada Masyarakat Bina Darma), 43-56.

Patimah, R. (2020, Mei 12). https://www.sekolahguruindonesia.net/praktek-edit-video-melaluiaplikasi-gratis-di-android/. Retrieved from Sekolah Guru Indonesia: https://www.sekolahguruindonesia.net/praktek-edit-video-melalui-aplikasi-gratis-diandroid/

Tian, M., Desi, C., Hardini, S., \& Indriani, P. (2021). Ruang Belajar Online Sebagai Implementasi Pembelajaran Daring Pada Murid SekolahDasar Muhammadiyah 22 Meranjat. JPKMBD(Jurnal Pengabdian Kepada Masyarakat Bina Darma), 43-56. doi:https://doi.org/10.33557/pengabdian.v1i1.1341

Widiono, A. (2021). Penerapan Aplikasi Kinemaster dalam Pembelajaran IPA melalui LMS pada. Prosiding Webinar Nasional IAHN-TP Palangka Raya, No. 3 Tahun 2021 (pp. 12-21). Palangkaraya: IAHN-TP Palangka Raya. Retrieved from https://prosiding.iahntp.ac.id 